Cultural activities, innovative milieus and urban policies:

a comparison of two districts in the city of Lisbon

Pedro Costa

October 2010

WP n. $2010 / 04$

DOCUMENTO DE TRABALHO

WORKI NG PAPER 
Cultural activities, innovative milieus and urban policies: a comparison of two districts in the city of Lisbon Pedro Costa* WP n. $.2010 / 04$ October 2010

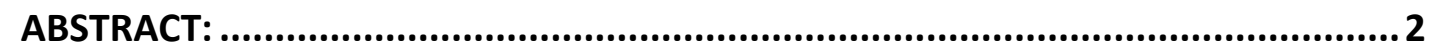

1. INTRODUCTION ..............................................................................................

2. THE CONCEPTUAL FRAMEWORK: CULTURAL ACTIVITIES AND TERRITORIALIZED

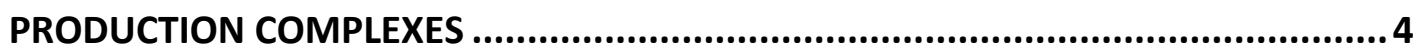

3. THE BAIRRO ALTO - CHIADO …...............................................................

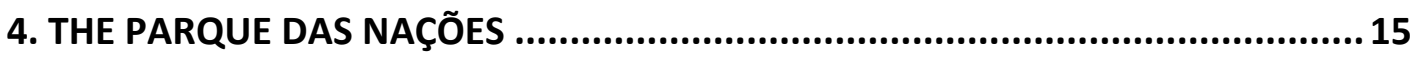

5. GOVERNANCE, MILIEU EFFECTS AND INNOVATION: SOME FINAL REMARKS .. 22

6. CONCLUDING NOTE: IMPLICATIONS FOR URBAN POLICIES................................26

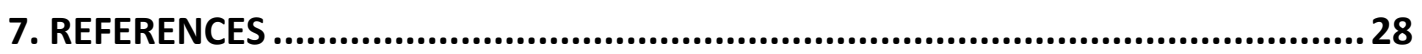

\footnotetext{
* DINÂMIA-CET/IUL.
} 


\title{
Cultural activities, innovative milieus and urban policies: a comparison of two districts in the city of Lisbon
}

\begin{abstract}
:
This paper explores the relation between cultural-led territorialized production complexes and the mechanisms behind the creative dynamics which are found there, focusing on some conclusions of two case studies conducted in Lisbon, Portugal: the 'Bairro Alto - Chiado' area (a typical cultural quarter in the historical center of the city), and the 'Parque das Nações' district (a recently regenerated old industrial area).

The analysis centers on the 'milieu' effects, the innovation dynamics and the governance modes specifically developed in those areas so as to shed light on the mechanisms behind their sustainability and competitiveness.

Drawing on these highly contrasting experiences, some general assumptions are emphasized on the relation between territory and the development of successful local production systems based on cultural activities.
\end{abstract}

\section{Keywords:}

Cultural activities; Innovative milieu; Urban development policies; Lisbon; Governance; Cultural quarters; Urban regeneration; Image producing complexes. 


\section{INTRODUCTION ${ }^{1}$}

In recent years there has been growing interest in territorialized production complexes based on cultural activities as it becomes increasingly apparent that these activities are central to the promotion of regional development and urban competitiveness.

The purpose of this paper is to understand the mechanisms underlying the creative and innovative dynamics found in some of these areas, drawing attention to the relations between these territorial agglomerations and those mechanisms. The analysis is focused on conclusions from two recent empirical case studies conducted by the author in two different areas of the city of Lisbon, in Portugal.

On one hand, the 'Bairro Alto - Chiado' area is a typical cultural quarter in the historical center of the city. It is a good example of the agglomeration of cultural activities in a central quarter in the heart of a metropolitan area and its effects. It concentrates a huge variety of cultural production and consumption processes in the most diverse areas of the wide-ranging cluster of cultural activities.

On the other hand, the 'Parque das Nações' is a district in the old industrial and harbor area in the east of the city which was recently renovated in preparation for the 1998 Universal Exhibition held in that zone of the city. After the exhibition, a specific planning process and governance scheme was adopted for the area which involved concentrating a great variety of new promising economic activities including several related to the cultural field.

Our research is centered on the 'milieu' effects, the innovation dynamics and the governance forms which develop specifically in these two areas so as to shed light on the mechanisms that allow or hamper the sustainable affirmation and competitiveness of each of these districts.

Our purpose is not to fully explore and specify all the empirical results of these case studies (this is done elsewhere - e.g. Costa 2003a, 2004), but to confront and discuss the main conclusions drawn in the two situations from the perspective of the innovative milieu concept, evaluating at the same time the robustness of this approach for this purpose.

The next section gives an overview of the conceptual relation between cultural activities, territory, territorialized production complexes, and innovative milieus in order to introduce the subsequent analysis.

Sections 3 and 4 focus on the two different case studies and their main achievements: first, the "Bairro Alto - Chiado" cultural quarter in the historical center of Lisbon; secondly, the

\footnotetext{
${ }^{1}$ This text is a revised version of two papers, previously presented by the author, to the 13th International Conference on Cultural Economics (The Association for Cultural Economics International), 3-5 J une 2004, University of Illinois, Chicago, USA, and to the 3rd Annual Conference of the "Old Industrial Knowledges" Working Group of the Regional Studies Association, "The Role of Culture in the Economic Development of Old Industrial Regions", 28th-30th J anuary 2007, University of Twente, Enschede, The Netherlands.
} 
regenerated "Parque das Nações" district - the former harbor and industrial area in the east of the city.

In Section 5 we briefly compare the results of the two case studies, focusing on their forms of governance, innovation and sustainability. We go from these two experiences (with very different origins, actors, and governance models, but also with very distinct markets in terms of cultural activities) to some pragmatic assumptions aimed at helping improve the knowledge about the relation between territory and the development of successful culture-led local production systems.

Finally, section 6 concludes by highlighting some significant issues with reference to policy implications (particularly concerning the city’s vitality and urban development) and stressing their role in this kind of territorialized production systems that are based on cultural and creative activities.

\section{THE CONCEPTUAL FRAMEWORK: CULTURAL ACTIVITIES AND TERRITORIALIZED PRODUCTION COMPLEXES}

Vibrant localized production systems based on the agglomeration of cultural and creative activities have been persistently emphasized in recent years by theoretical (or more conceptual) approaches and by empirical evidence and policy-making (for a systematization of this, see Costa, 2007; Costa et al., 2006). Multiple examples can be found in various fields ranging from geography or urban management to industrial economics or cultural studies if we examine academic research and policy strategies developed in the last years throughout the world. The many examples of this include: the development of art/cultural districts; the cultural dynamics in the centers of big metropolises; localized clusters based on a certain cultural product; high tech complexes related with the production of creative goods; image-production complexes; urban renewal operations based on cultural facilities or on large cultural events; or cultural quarters (e.g., Scott, 2000, ERICarts, 2002; Camagni et al., 2004; Lazzeretti, 2004; Bianchini and Parkinson, 1993; Hutton, 2000; O’Connor and Wynne, 1996; Santagata, 2002; Markusen, 2006a; EC/KEA, 2006; OECD, 2005). They all configure different kinds of territorialized production (and consumption) complexes, strongly based on cultural activities or driven by culture or creativity.

Some of these dynamic situations result from specific cultural or urban policy actions but many other rely on other kinds of governance mechanisms, most diverse. In any case, their effects in terms of territorial development obviously cannot be assessed solely in terms of their economic impacts and should be seen in the framework of the several dimensions of a sustainable territorial development process; this includes economic efficiency, of course, but 
also social equity, environmental quality, civic participation and cultural expression (see e.g. Costa, 2007 on this). Despite many misunderstandings and several “cultural” interventions in urban regeneration which end up to be somehow "destructive" to cultural development, the idea of culture-led regeneration did however produce some significant results. It did engender an obligation for cultural institutions to become active within urban policy construction and to reconceptualize their cultural activities and facilities in terms of a coherent 'cultural infrastructure' (Vickery, 2007). As Graeme Evans seminal study indicated a degree of cultural planning emerged with regeneration imperatives (Evans, 2001) introducing a conceptual framework within which (at least) cultural services became subject to broader social and urban policy questions and issues. Despite the several kinds of cultural renovation processes that can be identified (e.g. Evans, 2001; Ericarts, 2002) effects and benefits can be recognized in a variety of aspects (economic, social, human, environmental).

This issue is actually appearing in several other ongoing debates in academic literature, institutional documents and reports, and policy-making: these include the discussion on creative city and creative classes or debates on issues such as; the patterns of cultural practices and their dynamics; the industrial organization of cultural activities and creative industries; the specific economic problems and some particular forms of governance in the cultural activities; the fundamental role of cultural gatekeepers; or the discussion on the relation between creativity, innovation and value creation. All these issues have been brought to these debates by outstanding contributions from, for example, Florida (2002), Landry (2000), Caves (2002), Greffe (2002), Scott (2006), Markusen (2006), Asheim et al. (2007) or NESTA (2006).

However, regardless all these debates, the main idea that we can draw out from this is undoubtedly the importance of the difference that geography and space make in the organization of cultural and creative activities and, above all, their deep territoriality. In effect, cultural activities are found to be strongly embedded and linked to the territory and this can easily lead to the agglomeration of cultural production and consumption in robustly territorialized complexes, benefiting from scale effects and externalities.

In fact, there is strong evidence of this deep relation in all kinds of cultural activities albeit with different patterns and degrees of intensity (cf. Costa, 2003)². This is particularly true

\footnotetext{
${ }^{2}$ These territorial effects are clearly differentiated and related to each of kind of cultural activities - on this, see the typology developed in Costa (2003) expressing 6 different kinds of cultural activities in terms of their relation to territory: the core of cultural industries; the "cultivated", "institutional", "legitimated" culture; the popular culture related to urban sociability; heritage and historical-cultural preservation; the "techno-creative" activities; and amateur practices and other forms of cultural sociability. The stronger links to territory are particularly noticeable in creation/production of cultural goods/services and in their consumption; (the initial and terminal phases of the value chain) when compared with distribution which is much more de-territorialized.
} 
in the specific case of creative activities (or creative parts of the cultural production process) ${ }^{3}$. The concept of "image-producing complexes" (Scott, 2000) is particularly appealing to us here as it explores fundamental features such as the agglomeration of creative workers and firms in dense networks of SME's, benefiting from external economies (by location and agglomeration), and developing specific productive processes and particular use of technology, skills and labor relations, with a view to creativity and innovation. Their access to critical overhead services and important information flows, usually in a context of strong strategic cooperation, is revealed to be extremely relevant and can be enhanced by the most diverse governance forms and regulating mechanisms.

This territorial concentration, particularly important in project-based activities such as cultural and creative production, benefit strongly from interdependent network operation, seizing flexible local labor markets and competing by qualitative attributes (Scott, 2006). Obviously this oils the local productive system and improves the external competitiveness of those economic agents. But the amassment of cultural capital which is generated becomes an essential engine for additional relevant goals, such as the vitalization or regeneration of the social fabric, the generation of systematic opportunities for social networking and the access to cultural gatekeeping processes, increasing opportunities in terms of social, civic and (multi)cultural expression, and of course, increasing social and cultural capital personal stocks.

The combination of endogenous and exogenous factors is fundamental in these kinds of localized production complexes as it affirms their specificity (and consequently, their competitiveness) in a global context: on one hand advantage is taken of the specific production conditions of each place (influenced by a locally embedded culture, individually appropriable as a competitive advantage); on the other hand, becoming part of broader flexible specialization structures or in vertically dis-integrated production systems.

Note that this should be seen in the context of a broader and complex articulation between local and global socio-economic mechanisms where cultural products should be seen as the result of collective action (above all, in a sector with particular economic issues). It is therefore of fundamental importance both to understand the specific local governance mechanisms and to act accordingly ${ }^{4}$. In this context it is vital to consider the strategic agents that explore the interface with (increasingly global, though specific) markets, and particularly,

\footnotetext{
${ }^{3}$ For an introductory discussion on the distinction between creative and cultural activities see Costa et al. (2006).

${ }^{4}$ That is why is not easy, or even possible, to defend a culture-led local development model which would be considered the "activator" of these dynamics. They result from a specific combination of exogenous and endogenous factors, in each place, which can engender an institutional solution and a governance model that can be the specific source of their success and their sustainability over time (be it an autonomous cultural district or image-producing complex, or a territorially embedded cluster perfectly inserted in terms of vertical integration of the global value chains).
} 
the role of cultural gatekeepers; the articulation with the most diverse territorial patterns found in cultural consumption practices must also be understood.

Indeed, we have already suggested the hypothesis that these territorial production complexes are related to the existence and development of certain "milieu effects", in line with the approaches traditionally developed by GREMI researchers (e.g., Crevoisier and Camagni, 2000), and made a theoretical and empirical analysis of the relation between these culture-led territorialized production complexes and the existence of specific "milieu effects" (Costa, 2003, 2004).

This analytical framework is particularly pertinent and appealing as the Innovative Milieu (IM) approach enables us to address a variety of economic, social and cultural factors which underlie these dynamics. More importantly, it allows us to highlight the role of governance forms and social representations (and conventions) which seem to be even more fundamental in explaining the agglomeration of certain creative and cultural activities.

In effect, the opportunity arises for an "Innovative Milieu” situation when we encounter these territorialized production systems that are based on cultural activities. That situation is characterized by the existence of (i) a particular, territorially embedded, technical-productive system; (ii) a specific governance system; and (iii) a specific, strong collective (internal and external) representations system (Maillat, 1998), endorsing a specific "milieu” in that territorial system, propitious to the development of cultural activities (allowing a specificity to be offered which converts into a strong competitive advantage for that territory).

This condition relies on the development of a specific interaction logic amongst local actors based on networks, the valorization of relational capital and a strong evaluativenormative scene; it also results from the building of a collective work space and collective learning dynamics as well as the development of a solid innovation capacity that takes advantage of the ambiance, know-how transfer, personal contacts, formal and informal cooperation and tacit information circulation ${ }^{5}$.

This can provide some territorial specificity which can be the key to the competitive advantage offered by a certain agent in a certain place when developing a cultural project or providing cultural goods.

These kinds of agglomerative dynamics are easily compatible with the trend towards flexible specialization processes in cultural activities, particularly with the growing tendency to center activity in specific "work platforms" associated to project based networks. Flexible organizations of this type, predominant in most creative and cultural activities, require effectively strong agglomeration as it reduces transaction costs, improves knowledge,

\footnotetext{
${ }^{5}$ Though this is true for all kinds of activities, it is particularly so for some, namely those related to urban culture and urban sociability, the $4^{\text {th }}$ group of activities defined by Costa (2003) - see note 1. 
information flows, personal contacts, etc.; therefore, naturally cultural activities tend to agglomerate in some areas. Most creative or innovative practices or products are particularly favorable to concentration in a territory and in specific parts of urban space above all (e.g., Shapiro et al., 1992; Storper and Christopherson, 1987; Scott, 2000; Caves, 2002).

These dynamics are also in line with some of the most relevant factors considered determinant in the production and legitimization mechanisms of cultural products in the fields of cultural sociology (Becker, 1982; DiMaggio, 1987; Crane, 1992) or industrial and cultural economics (Caves, 2202; Greffe, 2002; Throsby, 2001; Towse, 2003), such as the belonging to specific "art worlds", the role of cultural gatekeepers, the effects of distinction on consumption practices, etc.

Within this general conceptual framework, the next two sections of this paper outline some conclusions from the two case studies which focused our analysis on the city of Lisbon. The two situations are quite distinct in both their origins and main features: one involves the main cultural quarter of the city located in the traditional historical center (the Bairro Alto and Chiado area) while the other (the Parque das Nações district), is a former industrial area which was renewed in preparation for a large international exhibition (EXPO’98).

These two case studies were chosen for this paper due to their relevance in cultural context of metropolitan Lisbon and their "tipicity" with reference to the most widespread analysis held internationally in this field in recent years: on one hand, cultural districts, and on the other hand urban regeneration operations, more or less linked to flagship facilities or outstanding events ${ }^{6}$

In the first case, the "Bairro Alto - Chiado" case study, the findings presented here result largely from an analysis made in the context of a finished research project (conducted in the scope of the above mentioned international research network GREMI - Groupe de Recherche Européen sur les Milieux Innovateurs) - (Costa, 2003a, Costa, 2004).

This work involved extensive field work including a vast survey and a few in-depth interviews with almost 200 cultural providers of the area. Our analysis was one of a set of empirical case studies in various European countries (Camagni et al., 2004) and our aim was to answer two main questions: is there an Innovative Milieu situation in this case? And is it sustainable? Since presenting the main results of this study (Costa, 2004; 2003; 2003a) we have continued to closely observe and monitor the recent evolution of the quarter where some significant contextual and institutional evolutions have taken place meanwhile.

\footnotetext{
${ }^{6}$ Clearly other cases could be also interesting for this study, ranging from the heritage and museums complexes e.g. Belém area, to specific and interesting governance schemes which start to emerge in the city e.g., Santos Design District. However, the former are the most relevant for our purposes, considering our interest in the innovative milieu approach.
} 
In the second case ("Parque das Nações"), the results presented here relate to an ongoing research project conducted from a different perspective and based on distinct conceptual and methodological approaches. Based mostly on a documental analysis, the main goal of the study was slightly different and led to another question: assuming that this is not an innovative milieu situation would it still be a sustainable case of territorial dynamism based on cultural activities?

With these differences in mind, the next two sections compare some of the main outcomes of the research conducted in these cases. Our purpose is not to detail the achievements identified in each of these studies, but only to evidence and compare their main conclusions from the perspective of our conceptual framework based on innovative milieu. Section 3 therefore examines the old cultural district "Bairro Alto - Chiado" and section 4 presents the case of the recently regenerated harbor area renamed "Parque das Nações".

\section{THE BAIRRO ALTO - CHIADO}

The Bairro Alto - Chiado area is the main and ancient cultural quarter of Lisbon city, that goes back to the $15^{\text {th }}$ century. In fact, this area can be seen as the aggregation of two different though complementary realities (see Costa, 2003a for details): the Bairro Alto and the Chiado. Nonetheless, they have always been interconnected and complementary throughout history, like two sides of the same coin, one of which is more institutional, diurnal and formal (Chiado), and the other more transgressive, nocturnal, marginal and independent (Bairro Alto).

The Bairro Alto section essentially continues to be a residential area nowadays; it is one of the city's typical old quarters marked by "fado" and bohemia where a special gentrification process has gathered pace particularly in the last two and a half decades. In effect, the appropriation of space by a set of persons and activities related to entertainment, leisure and culture that highlight the aesthetics of daily life is visible in this quarter (like many other cultural quarters in many European cities).

As a result, the main cultural activities in this area are diverse, and nowadays can be roughly divided into 3 main groups: (i) some traditional small handicraft activities (e.g. bookbinders, restorers, upholsterers, gilders), that continue to survive in this neighborhood; (ii) some core cultural sub-clusters (e.g. performing and visual arts, antiques, edition-printing cluster) that are geographically significant in this part of town; and (iii), increasingly influential, many small agents from the new, more youth-oriented cultural industries (e.g. fashion, nightlife, design and aesthetic-symbolic oriented retail, independent performing and visual arts, etc).

The Chiado section can to some extent be seen as a complement to Bairro Alto. It is one of the traditional city's centers of commerce and service offices, which has been greatly affected 
by residential desertification, the tertiarization process, and all the functional changes within the city and metropolitan organization. It remains one of the city's most distinguished commercial zones and is a symbol of Lisbon's culture and intellectuality for many centuries. However, the area was partially destroyed by a fire in 1988 and all the delays in the rebuilding and recovery process, as well as the development of new commercial dynamics in other parts of town, meant that much of the traditional commercial dynamism was lost until the mid 90's. Only now is it beginning to recover.

Chiado’s main cultural activities have a more institutionalized and conventional pattern in the shape of market oriented cultural industries, above all book publishers and bookshops, (as well as the more erudite and classic "high" forms of artistic expression, thanks to the great concentration of theaters, performing arts, opera, classical music, museums and art galleries.

If the area as a whole (Bairro Alto plus Chiado) is considered, as two complementary sides of the same coin, and if this "extended" cultural quarter is seen as a resource for urban development, some critical factors can be noted that shed light on the evolution of the whole area and the possible competitive advantages of this cultural "resource". These include aspects that have a positive and negative influence on the quarter's evolution, such as (Costa, 2003a, 2004):

- The desertification and gentrification process in the area: much more "artistic and aesthetic lifestyle" oriented in Bairro Alto, and more "prestige and economic capital" oriented in Chiado;

- The process of post-fire ${ }^{7}$ reconstruction in Chiado and the regeneration dynamics (both residential and commercial) in the area (and its delays);

- The significant increase in land prices (linked to the socio-economic and cultural change in the composition of the population and its effects on the functional organization of territory);

- The role of the new economic cultural activities; particularly, the new youth subcultures closely associated to the ambience of artistic-marginality and creativity;

- Improved access (particularly with the subway extension), which allowed the centrality of this zone in the metropolitan area to be enhanced;

- Structural problems of parking and traffic which still severely affect the city center and this area in particular;

- The issue of drug trafficking and petty crime affecting part of this area, mainly in Bairro Alto;

- The development of other new centralities in the city, with the structural re-composition dynamics registered over the last two decades in Lisbon metropolitan area;

- The exit of the main agents of several cultural subclusters (e.g. press, art schools, and some marketsegments in nightlife or decoration) to outer areas of metropolitan Lisbon; and,

\footnotetext{
${ }^{7}$ Chiado area was gutted by a huge fire in 1988.

DINÂMIA/CET - IUL, Centro de Estudos sobre a Mudança Socioeconómica e o Território ISCTE-IUL - Av. das Forças Armadas, 1649-026 Lisboa, PORTUGAL

Tel. 217938638 Fax. 217940042 E-mail: dinamia@iscte.pt www.dinamiacet.iscte.pt
} 
- Some problems linked to use conflicts verified internally to the exploitation of this resource (mainly in Bairro Alto), between residents and users mostly linked to nightlife (e.g. externalities such as noise).

One the conclusions of this case study was that the actors in this territorial system are very diverse and cross several cultural and creative sectors: music, audiovisuals, antiques, book, edition and printing, creative offices (design, architecture, communication, etc.) nightlife, art galleries, museums, performing arts, visual arts, fashion, decoration, photography, art schools, and so on. However it is not easy to draw out a single typology of agents in terms of their activity or branch as their interrelation and behavior frequently cross over these artificial distinctions.

Crossing each of these sectors, a great diversity of practices and attitudes towards innovation is verified: some agents are potentially innovative within the system; others are noninnovative at all, and there are also some that are not integrated in the local production system at all.

Equally, the agents are very diverse in terms of their area of activity and main motivations. Four main kind of actors in the cultural domain can be identified, considering this diversity of rationalities and objectives (Costa, 2003, 2004): (i) the public or institutional cultural agents, that usually are of a greater dimension; (ii) the firms, which are clearly marketoriented; (iii) the small entrepreneurs, many of which are small associations or collectives of individual artists and creators, that are more artistic-creative oriented; and finally (iv) the various public regulators (both in cultural policy or other domains, and at local or supra-local levels). Naturally, the analysis of their behaviors and their interaction in this system most consider all this diversity.

In line with GREMI research program and our innovative milieu approach, our analysis focused on three central issues: identifying forms of governance that enhanced the development of this territorial system; detecting innovative behavior existing among cultural agents of the area; and recognizing any relevant conflicts in the use of this resource that could put its long term sustainability at risk.

Several aspects concerning the forms of governance and system regulation were identified as vital to the development of this area. Besides the evident importance of market structures and mechanisms, several other relevant forms were noted: the public regulators (both at local and central level); several localized associations and organizations (representing both specific territorial or corporative-professional concerns) playing a significant role in agents' collective action; the formal and informal networks which are locally established among these cultural and creative agents (often focused more on defending aesthetic/cultural/artistic ideals 
and certain lifestyles and representations than being directly market orientated); and, of course, the cultural gatekeepers and mediators (e.g. critics, decision makers in public support institutions, curators), who have a crucial role in the cultural and social legitimization of the artists. Even the specific dwelling typologies and living conditions in the neighborhood (e.g. the ambience, the particular lodging typologies, the high level of social control) can be invoked here. In effect, those conditions permit and foster a very specific lifestyle which tends to support an extremely selective gentrification process (at least, in Bairro Alto case), because only more artistic, creative and hedonistic orientated social strata aim for or are able to support certain living conditions. Similarly, the great local concentration of restaurants and nightlife (the largest in the city) plays an essential role as a central node in the diffusion of know-how, conviviality and in socializing, as well as in the development and affirmation of certain social representations.

All these regulation aspects allowed specific governance mechanisms and a common social representations system to be developed, internally and externally to the area, and were crucial to considering this cultural quarter as an innovative milieu situation (see more in Costa, 2004).

Figure 1: Conditions for the existence of an Innovative Milieu

\begin{tabular}{|l|l|}
\hline Localized production system & +++ \\
\hline Local intersectoral linkages & ++ \\
\hline Cooperation and synergy among firms & +++ \\
\hline Cooperation and synergy with the governance system & + , only in some activities / agents \\
\hline Presence of collective agents & + , but only in some activities \\
\hline Internal representation & +++ \\
\hline External representation & +++ \\
\hline Network cooperation with the external milieu & $-/+$, rarely \\
\hline Localized collective learning & ++ , only in some activities / agents \\
\hline
\end{tabular}

Figure 1 provides an overview of the various conditions that confirm the existence of an innovative milieu situation in Bairro Alto - Chiado area (Source: Costa 2004).

However, even if we consider this area an innovative milieu, another question regarding the innovative and creative behavior in this localized production system was important to us: what kind of innovative management of the resource we have here? The conclusions of this research highlighted two main dimensions to the development and the spread of innovation in this cultural quarter, and the agents (or at least some of them...) can benefit from both of these closely intertwined dimensions: on one hand, the innovative collective (and mostly informal) 
management of the quarter's evolution; this allowed its sustainability over the centuries, even with changes and restructurings in the main core of cultural activities existing in the area); and on the other hand, the innovative behavior of each of the agents (or at least some of them...), embedded in that innovative collective ambience.

Parallel to this, our aim was also to evaluate the long term sustainability of the dynamics of the area by analyzing the potential use conflicts that could compromise the cultural quarter's evolution. Several use conflicts were identified in the exploitation process of this cultural resource, that is, the cultural quarter's ambiance; and this is indicative of the diversity of activities, agents and ways of life that make up those neighborhoods: conflicts between residents and users; between traditional (elderly, with low income) and new (younger, better skilled) residents; between traditional and modern commerce and services activities; between day and night users; between the cultural agents (private, public, associations, individuals) and public regulators; amongst agents themselves due to market competition; or even other particular aspects related to marginality (drug trafficking, prostitution, etc...). The equilibrium achieved at each moment in all of these aspects and particularly in the most sensitive questions linked to nightlife externalities and to marginality and drugs, is a compromise between the different interests; this is strongly regulated by the largely informal governance mechanisms operating in the area.

With all these conflicts, the question of the sustainable management of the cultural quarter assumes great relevance. How has it been able to maintain its dynamism over the centuries? How can the resource exploitation be sustainable over time? This is even more relevant as the survey results revealed that local cultural agents evaluate the district's evolution very favorably although the public policies implemented in the area were given a poor evaluation.

The question of the qualification of the resource and its sustainability over time is thus crucial. Several factors were identified that can allow the sustainable development and competitive enhancement of this part of the city and agents were asked about their importance. The results (ordered by preferences) are shown in Figure 2. 
Figure 2: Crucial factors for the sustainability of the cultural quarter

\begin{tabular}{|c|c|}
\hline $\begin{array}{c}\text { Main factors identified for a sustainable development of the cultural quarter } \\
\text { (ordered by their level of quotation in the survey to local cultural agents) }\end{array}$ \\
\hline - & Resolution of traffic / parking problems; \\
- & Public space re-qualification; \\
- & Urban rehabilitation policies; \\
- & Incentives to cultural production; \\
- & Demographic revitalization; \\
- & Territorial marketing of the area; \\
- & Strategic anticipation in new cultural activities; \\
- & Support for information circulation between agents; \\
- & Reinforcement of the centrality in the city; \\
- & Increase of external interactions and networks; \\
& Firect public provision of cultural goods;
\end{tabular}

Source: own elaboration

This reveals a considerable belief in the self-regulatory dynamics of this territorial system and in the quarter's cultural provision; it also shows that cultural public intervention is not generally required, at least in such a direct and conventional way. In other words, agents seem to believe that this "cultural resource", that is the cultural quarter, will survive and sustain itself with its own self-regulatory governance mechanisms like an effective innovative milieu; they believe that the public intervention required mostly involves solving some contextual problems such are parking, traffic, urban qualification of public spaces, etc., as opposed to direct action on the cultural provision or even cultural support of the agents. Some public intervention which is less sensitive to these specific governance mechanisms could even be destructive to the system and cause more harm to the area than good, that is, than fulfill its direct objectives.

We conclude this brief summary of the findings of this study with the key points of this Bairro Alto - Chiado case study (Costa, 2004):

First, it was clearly confirmed the importance of territoriality to the running of these activities in the area: there is undoubted evidence of a strongly territorialized cultural production and consumption system.

Secondly, a "milieu" which is propitious to innovation and creativity is found. However, this may not be experienced by all agents (crossing the conventional sub-sectoral classifications), and the results suggest that the symbolic relations and agents' perceptions 
which were identified seem to overcome the effective material relations measured amongst most of the agents.

Thirdly, the area's specific and multiple governance mechanisms must be stressed. They play an essential role in the system regulation and cannot be easily found or reproduced in other parts of the town.

Fourthly, the sustainable management of this resource must be linked to its agents' extremely diverse motivations and rationalities (e.g. profit, aesthetic value, social affirmation, etc). Any conceptual framework that ignores this diversity e.g. based exclusively on economic rationality is not sufficient to understand its dynamics at their full extent.

Finally, all these issues clearly raise new stimulating challenges to the innovative milieu concept itself, which this and other parallel studies within the GREMI VI research program have demonstrated require specific improvements, such as acknowledging more "extraeconomic" driving forces on these processes, recognizing other intrinsic motivations and valuing agents multiple rationality, if it is intended to contribute to explain sustainable dynamics based on cultural and natural resources (see Camagni et al., 2004).

\section{THE PARQUE DAS NAÇÕES}

The Parque das Nações is an area which was rehabilitated for the 1998 Lisbon universal exhibition. It is strongly related to a particular governance mechanism, namely a partnership society, with public capital, that has been responsible for the management of the area and conducting the recovery and urban renewal investment process.

This case study involves a former industrial area along Lisbon's eastern riverfront that has been greatly affected by globalization and contemporary economic restructuring processes as well as by the functional transformations within the metropolitan territorial organization. It presented a clear opportunity for urban renewal and this led to the development of a regeneration project linked to hosting a large International Exhibition (Expo'98). The recovery of this area was achieved though an integrated operation that combined real estate, facilities and natural and public spaces with a strong carefully planned urban and architectural image. This was accomplished by means of strong public intervention in the area, and the creation of an institutional arrangement based on an innovative public company and the settlement of public private partnerships to assume regulatory control in many fields. The project aimed to transform the space into a residential and qualified services area, distinguished by its strong image in collective representations.

All these ingredients provided, this would be an excellent opportunity for the inclusion of cultural and creative assets and resources to bring new dynamics and vitalization to the area. 
Nevertheless, even now the main cultural activities taking place here present a pattern which is much more conventional than in the other case study presented above. From the perspective of cultural and creative activities, this project is essentially marked on one hand by the concentration of new facilities in the area and the location of some significant institutions in performing and visual arts, and, on the other hand, by the setting up of diversified marketoriented cultural industries and many small creative offices.

A brief overview of how the project evolved and developed can shed some light on this situation. The EXPO'98 project was developed as “The Last Exhibition of the 20th Century” between May and September 1998 with the specific focus of "The Oceans: A Heritage for the Future". Its main goals included highlighting the historic importance of the Portuguese discoveries in the late 15th century and encouraging the preservation of the oceans that cover $70 \%$ of the earth's surface and are not yet well understood.

In fact, the overall project incorporated two closely coordinated projects: holding the Lisbon World Exhibition, and also revitalizing an urban area covering nearly 340 hectares of ideally situated eastern-Lisbon riverfront real estate (including $5 \mathrm{~km}$ of river front property on the Tagus River estuary). The exhibition was in itself of great importance to the city and to national symbolic representations, but it also served to trigger urban recovery and the environmental cleanup at the site. At the same time, the urban renewal project provided an organizational, economic and financial structure which was then extended to the specific requirements of Exhibition's development.

The Parque das Nações urban development project covered this entire area and was thus the key to the whole operation. The first phase laid the foundations of the overall project: designed as a public space and hosting EXPO'98, it is a self-contained urban whole, with residential quarters, commerce, services, urban infrastructure, parking facilities and parks. The urban concept sought to re-establish the link between "the City" and "the River". Environment and landscape were to be restored, usefulness rediscovered. The development was to be woven into the city's fabric and contribute to defining the city as a whole while becoming a new pole of attraction in its own right within the greater Lisbon area.

The overall project combined the concerns to improve the environment, enhance urban renewal, and modernize and internationalize Lisbon and paid particular attention to several aspects which contributed decisively to its success. Besides using cutting edge technology in many fields for the physical infrastructure, care was taken to put great emphasis in innovative and modern architecture and landscaping. It was considered an opportunity to create a new city with innovative design associated to impressive landmarks and flagship facilities e.g., Portugal Pavilion, Luís de Camões Theatre, Vasco da Gama Tower, Oriente Railway Station. At the same time, the "anchoring" of this new pole in the city of Lisbon was assured by a set of 
fundamental project features: (i) easy access via various means of transport with priority given to public transport and pedestrian zones; (ii) a lively, well-situated collection of shops and services for a wide variety of tastes and budgets; (iii) an architectural contribution of unique, high quality "flagship" buildings consolidating a new urban skyline; and (iv) seeking to redefine the city's relationship with the river front.

Other important aspects at the heart of the original urban project include: the development of significant new urban landmarks (e.g. Lisbon Oceanarium, Vasco da Gama Shopping Center, International Fair of Lisbon, Atlantic Pavilion); the focus on landscape architecture from the perspective of humanizing the city together with an ambitious treeplanting program; and the promotion of urban art in public spaces, with the work of 24 artists exhibited in and around the Parque das Nações.

Above all, however, the success of the urban renewal and urban vitality of this part of the city was due to the combination of residential areas with a new business center and shopping and leisure areas that effectively implemented the multi-functionality of spaces. For instance, the Parque das Nações new residential and business areas are complemented by an extensive selection of shops and restaurants. The two effective anchors of the project in terms of urban centralities, namely the Vasco da Gama shopping center and the Oriente railway station, also feature a variety of services and shops which is essential to the dynamism of the area.

The overall urban renewal operation was an unambiguous success, despite some significant modifications during its implementation particularly due to the need to increase the densification in construction (in order to finance the project's budget overlaps). However, we must question whether it is really verified a culture-led territorial system.

Indeed, if we focus our inquiry specifically on a hypothetical territorial system made up of cultural and creative activities, a similar analysis can be made to that of the Bairro Alto Chiado area.

Considering that purpose, some critical factors can be identified that shed light on the evolution of that area and the possible competitive advantages of this local system; again, this is understood as our supposed "cultural resource", the ambiance of which could be seized by its cultural agents in their activity:

- Primarily, the re-population of the area and its gentrification ${ }^{8}$, regardless of the occurrence of strongly speculative real estate mechanisms (e.g. although sold, most houses remained unoccupied for the first years after the exhibition;

\footnotetext{
${ }^{8}$ Although gentrification could be a fuzzy concept here as this was not a very populated area before, but was essentially a disqualified industrial and harbour area.
} 
- Consequently, the large increase in land prices and the socio-economic-cultural transformation of the local population's composition, with evident effects on the functional organization of space, including new top business services activities;

- The possibility of relating with other (less-“cultural”) "creative activities” in clusters with a strong presence in the area (e.g., telecommunications), and of seizing the trend to relocate other cultural activities in nearby neighborhoods (e.g., audiovisual, recording studios, equipment, spreading through the surrounding eastern part of the city, with extensive and cheap property available in local real estate market);

- The post-Expo dynamics of the urban renewal implementation process (and the delays and changes in the original urban projects); this relates to the sustainability of the main form of governance running the area ("Parque Expo"), and the capacity to attract people and to keep cultural animation, as well as to enhance social and economic activity and the use of public spaces (notoriously animated, feed by a vast and growing hinterland in Lisbon metropolitan area, particularly its' northeast section);

- The new accesses provided by the road and public transport networks which make this zone much more central in the metropolis, particularly within the framework of its structural recomposition dynamics;

- The success of the area's image and marketing and its impacts on public and collective representations;

- The strength of the institutional model used to develop this operation, as it has been reproduced after that in several other Portuguese small towns, applying the know-how obtained to other urban recovery programs

The diversity of actors in this territorialized production system is also an important feature of this case study although it is clearly not so extensive as in the Bairro Alto - Chiado area. In fact, although there is a reasonable diversity of actors, it is just in some branches of the cultural and creative cluster: creative offices (e.g., advertising), visual arts, art galleries, museums, performing arts, nightlife, art schools, occasional agents in cultural industries (audiovisual, music, bookstores), etc.

Like in Bairro Alto - Chiado, some of these actors are potentially innovative while others essentially show no innovative behavior; however, unlike Bairro Alto - Chiado, most of them are not fully integrated in the local productive system.

In addition, although there are not so many agents here, the various types and motivations of cultural actors contrast greatly, providing potential for exploring complementarities: some large public or institutional cultural agents; the essentially marketoriented firms, most of which are SMEs; and public regulators in the various domains of policy making. However, here there is a lack of small and more artistic-creative oriented entrepreneurs (associations, small firms, independent arts professionals etc), contrasting strongly with the 
Bairro Alto - Chiado area where they were the largest and most and innovative) group in the cultural fabric.

It is the strong governance structure that seems to play a fundamental role in the development of this resource, with the institutional structure still running many of the aspects of the project development. The "Parque EXPO'98" company was legally formed in 1993 to design, execute, build, exploit and dismantle the Lisbon World Exhibition (EXPO 98), as well as to work in the urban renewal of the Lisbon Eastern area where the Exhibition site was located. After EXPO'98 (and its transition to “Parque das Nações”), the Parque EXPO’98 adapted itself to new business areas, devoting to diverse intervention in urban and spatial planning, such as the rehabilitation and renewal of architectural heritage, now outside the origin area, without any geographical limitations. Today, Parque EXPO is a public limited company and its capital is owned by the Portuguese State (99.1\%) and Lisbon City Hall (0.9\%).

The firm's scope of action has therefore broadened considerably. The "chairman's message", in the institutional website of the firm is very illustrative on this:

"Parque Expo has as mission to transform land, promoting urban life quality and cities competitiveness, operating urban and environment renewals, developing social, environmental, economical and cultural sides in an integrated way and always bearing in mind the sustained urban development.

It is a tool of political policies of space planning and revitalization of cities, acting as platform of good understanding with private initiatives.

Parque Expo's product is the sustained city. Therefore, the company is in itself a skills centre with a board of highly qualified technicians, owner of its own approach developed by multidisciplinary teams, capable of managing great, ambitious and sustained projects, with excellent environmental, social and financial results.(...)”

(Quotation from the "Chairman message" from the Parque Expo website: http://www.parqueexpo.pt/site/parexpo_ctexto_00.asp?ctextolocalid=1)

As a public company, to a certain extent Parque EXPO reflects some of the basic principles of the state policy on spatial planning. Thus, it executes some of these policies and establishes a link between persons in charge and investors, notably by fostering public/private partnerships and in particular in the context of state-backed urban renewal operations in a number of cities. Parque EXPO activities involve assessment studies to determine operational sustainability; the promotion and participation in special purposes vehicles, associating partners with the right profile to project specificities; fund raising; and project management. Their aim is to assure private investments get positive results whilst guaranteeing the coherency of urban regeneration operations. In other words, although achieving these goals involves a share in the 
implicit risks, Parque EXPO ensures the urban transformation process is efficient within the framework of its social and political goals.

Today, Parque EXPO runs several operations in more than a dozen Portuguese cities. These are mainly as partnerships in the framework of a vast government program for the regeneration of historical city centers - "POLIS". They also operate abroad, namely in Brazil and are now entering other markets in Eastern Europe and Northern Africa.

Returning to our "innovative milieu" analysis in the Parque das Nações area, where Parque EXPO’s activity originated, we now systematize the conclusions regarding the same key questions covered in the study of the Bairro Alto -Chiado cultural district. We examine the forms of governance sustaining this territorial system, any relevant innovative behavior therein, and any conflicts detected that could compromise the long term management and sustainability of this resource.

The forms of governance and system regulation have essentially been described above. Reference should be made to the importance of the market mechanisms and structures and to the general responsibility of public regulators both at local and central levels, but above all to the fundamental role of the institutional structure managing the area i.e. the Parque EXPO company.

Nevertheless, other mechanisms are found with some relevance in the regulation of this territorial system. The role of cultural mediators (e.g. critics, decision makers in public support institutions, curators) can never be underestimated in these activities ${ }^{9}$. The dynamics of nightlife and restaurants enhance conviviality and therefore urban vibrancy, although this is much more generalist and less creative-oriented than in the cultural quarter of Bairro Alto-Chiado). Finally, agents can explore the insertion in (much more) de-territorialized networks (mostly oriented by aesthetic/cultural/artistic values).

What insights can be drawn regarding the innovative and creative capacity found in this case study? Clearly, no innovative milieu is found. Despite the considerable local concentration of cultural activities and facilities, the situation is very different from that of Bairro AltoChiado. Moreover, the "cultural ambiance" and sense of belonging that were central to there are not encountered here at all. Even though there is a strong governance mechanism in Parque das Nações, its local productive system is much weaker and the collective representations system that exists is unrelated to these cultural and creative activities. None of the effects expected in an effective milieu situation e.g., collaboration between agents, collective learning processes, local diffusion of know-how and innovation, are consistently found, not even a proper local and territorially embedded production system solidly centered on certain specific activities (in this case the cultural and creative cluster).

\footnotetext{
${ }^{9}$ But which are here much less locally embedded and more de-territorialized than in the other case study. 
But anyhow is there any kind of innovative management of the resource? In fact, some agents benefit from agglomeration, from urban space quality and, above all, from a form of governance that supports the experience, in their activity. Although there may be some individual innovative behavior by a number of agents (though not too cooperative), a collective innovative solution in the management of the cultural resource is unlikely to be found here.

The use conflicts in this cultural resource exploitation are not so relevant here as in Bairro Alto - Chiado (apart from the market itself) due in part to the powerful role of the governance mechanisms in the area (providing certain institutional solutions that regulate potential conflicts - e.g., noise, public space occupation and degradation, etc).

Despite this low level of perceptible conflict, the question of the sustainability of the exploitation of this resource over time must still be asked. Here, the prevailing conviction is that the qualification of the resource undoubtedly depends on the "centralized" structure running the area (and solving problems in public spaces, promoting the local image, attracting firms, amongst many other functions). The self-regulatory dynamics in cultural provision that have always been the key to sustainability in Bairro Alto - Chiado are clearly not found here. In Parque das Nações, there is an evident dependence on a single, centralized and above all, statesupported institutional solution together with a reliance on the sustainability of this structure.

In short, the following conclusions can therefore be drawn from this brief description of the "Parque das Nações" case study.

First, although not directly related to a strong cultural cluster, the importance of territoriality in this area's development is confirmed. There are signs of an emergent local production and consumption system based on cultural activities, albeit much less locally embedded than in the other case study.

Secondly, despite a dynamic situation promoted by a powerful institutional agent, there is no "innovative milieu" situation, propitious to innovation and creativity. This may be lead to cultural agents obtaining much more than just the conventional agglomeration economies and transaction costs reductions closely related to spatial concentration.

Thirdly, the governance mechanisms and particularly the "Parque Expo" company (and partnerships, in several areas) play a decisive role in the regulation of this territorial system.

Finally, this system is characterized by a set of much more conventional activities and agents whose competitive advantages are very dependent on the governance mechanisms of the area. At least for now the long-term sustainable management of the resource (as a cultural territorialized production system) is intimately linked to the success and vitality of the institutional structure which supports it.

DINÂMIA/CET - IUL, Centro de Estudos sobre a Mudança Socioeconómica e o Território 


\section{GOVERNANCE, MILIEU EFFECTS AND INNOVATION: SOME FINAL REMARKS}

Some general comments can be drawn from the comparison of these two case studies. Figure 3 presents the key aspects in light of the three main dimensions structuring our analysis of the case studies i.e. the existence of innovative milieu effects, the subsistence of specific and strong governance forms, and the capacity to generate and maintain innovation and creativity.

Figure 3: Comparison between the two case studies

\begin{tabular}{|c|c|c|}
\hline & Bairro Alto - Chiado & Parque das Nações \\
\hline Milieu effects & Partially verified & Not verified \\
\hline Governance forms & $\begin{array}{c}\text { Very diversified, allowing } \\
\text { some self-regulatory } \\
\text { capacity in some fields }\end{array}$ & $\begin{array}{c}\text { Dependence (at least } \\
\text { initial) on the main } \\
\text { institutional structure }\end{array}$ \\
\hline $\begin{array}{c}\text { Innovation and } \\
\text { creativity }\end{array}$ & $\begin{array}{c}\text { Individual innovative } \\
\text { behaviors, but also } \\
\text { diffusion of innovation } \\
\text { through the milieu }\end{array}$ & $\begin{array}{c}\text { Occasional individual } \\
\text { innovative experiences, } \\
\text { with much less diffusion }\end{array}$ \\
\hline
\end{tabular}

Source: own elaboration

Indeed, we recognize that the Bairro Alto - Chiado has a consistent and sustainable situation of cultural-led territorial dynamics in the form of a well-defined socio-economic production and consumption system where (at least most of) the effects expected in an innovative milieu situation occur. Innovation relies not only on the potential individual behavior of each agent but also on the collective management of the resource that is linked to the ambience breed in that cultural quarter. The governance of the system is much more diffuse in this case study; however, it is this spread form of self-regulation that has allowed constant adaptation over the centuries. Although its core activities have sometimes changed, its liveliness, cultural vibrancy and long term sustainability have never been compromised.

In contrast, the cultural dynamics of Parque das Nações are intimately linked to and dependent on a particular governance model that happens to be much more concrete and concentrated. The special effects which characterize an innovative milieu situation are not found and it is even hard to defend the categorization of this area as a contained and sustainable cultural-led local productive system. There is some cultural activity locally concentrated with strong growth potential; although there are of course occasional individual innovative and creative experiences by some cultural agents, the collective dynamics of diffusion of knowhow, 
learning, collaboration and even self-representations are at a much lower level than in the other case study.

The completely distinct governance mechanisms which are the base of each territorial system express of course two most diverse situations in terms of cultural policy and even urban policy. In Parque das Nações the public action (even "indirectly", via a specific public company) is clear, explicit and indispensable; in Bairro Alto - Chiado, it is not explicit or direct (at least in a culture-led urban regeneration perspective) and has always been conducted, over the times, in a casuistic, disarticulated and non-systematic manner.

A comparison of the cases naturally reveals a significant disparity in social displacement factors. While both involve a certain gentrification process and the attraction of new inhabitants and economic functions, significant differences are found. In the Bairro Alto and Chiado area the attraction of the "creative classes" (at least the "cultural" part of it), who replaced the elderly local population is much more visible. It has assumed the form of a typical gentrification process albeit with the above mentioned distinctions between the two sub-areas: more aesthetically-oriented and vibrancy-led in Bairro Alto and more wealthy-driven in Chiado. In contrast, the big demographic and economic growth in the previously scarcely populated area of Parque das Nações comprises mostly well-off, urban young or middle-aged families, who do not necessarily have particular cultural inclinations or prominent culture-led lifestyles.

In line with most of the recent academic production in the field of cultural or creativityled territorial development analysis and strategies, this leads us to the question of how to enhance and foster cultural-led urban competitiveness and creativity-based development (on this, see e.g., Ebert et al., 1994, Bianchini and Landry, 2004; Hall 2000; Scott, 2006; Markusen, 2006a; EC/KEA, 2006; OECD, 2005; NESTA, 2006). Could either of these ways lead us to the so-called creative city?

Our case studies have some similarities with many others in Europe and elsewhere which have been brought to light in recent years including both of these ideal-types of successful “cultural-led” experiences i.e. cultural quarter's dynamics vs large urban renewal operations or large events.

The Research Institute for Comparative Cultural Policy and the Arts (ERICarts 2002) have examined this diversity in an exemplary fashion in a wide set of case studies with successful relations between artistic creativity, cultural governance, innovative management and urban development. As a result of the multiplicity of situations and cases identified, four different dimensions were proposed in this work to explain the diversity of successful experiences observed and to shed light on the triangle “territory - milieu - cultural creativity': (i) the cultural conditions: some experiences were based on the abundance of indigenous supply; others on the scarcity of indigenous supply; others on the presence of intercultural influences; 
(ii) the territorial conditions: some experiences relied on agglomeration and concentration; others on high level of networking, others benefited from marginalization and closure; (iii) the 'genetic' characteristics of the initiative: some cases demonstrated creativity as a set of emergence phenomena; in other cases, it was the presence of specific "creativity-relevant' policies; others resulted from specific cultural motivations; and (iv) their effects: some of those experiences reveal cultural wealth; others worked as key elements in local development; others essentially enhanced territorial resources.

This framework demonstrates the need to work on developing our conceptual tools so as to further our knowledge of these activities and seize the quite unexplored potential that can be used to help design and implement specific policies that foster urban creative-led development. Moreover, it leads us to the same issue that arises from our two case studies. Like in many of those conceptual and empirical observations, we stress here that policy-action in these cases must go beyond simply promoting cultural facilities and events or even supporting cultural agents; going further than all that, it must move from expecting just to benefit from its isolated effects to the "erection" of an effective "creative city".

Although the success of various experiences studied in recent years is due to multiple factors, the importance of issues like articulation between agents, regulation, and insertion in the city and in global or external networks (e.g., of cultural goods trade, of images and symbols, of cultural mediation processes), always seems to be underlined. It is not only one facility, event or institution working in isolation, but the development of its cultural work in articulation with the context and resources of the city in which it is inserted.

Some preliminary policy implications can be drawn regarding the most suitable public action for the sustainable development of these areas. The multidimensionality of intervention seems fundamental here both in terms of urban development and cultural policies and regardless of the scale of action and level of public participation in the governance systems. But, most importantly, extreme care must be taken with the system's forms of governance and the specificities of local circumstances. In other words, the specificities of local actors, institutions, relations, networks, expectations, motivations must be considered and a appropriate and specific institutional solutions must be designed (or supported, if pre-existent) for each case. And this will almost certainly be impossible to reproduce in any other situation.

For instance, in our Bairro Alto - Chiado case, the governance of the cultural quarter resource and its sustainability rely on a complex set of issues (and delicate equilibriums) that have kept it working successfully for centuries but which are not easily replicable in other parts of the city. But they are also fragile conditions that evolve over time and can also be put at risk by internal or external actions. For instance, despite the belief manifested by its cultural agents

DINÂMIA/CET - IUL, Centro de Estudos sobre a Mudança Socioeconómica e o Território 
on a certain self-regulation of the system and the superfluous nature of public cultural action in the area, even public action can be questioned in this matter.

In fact, there have been some examples of public intervention in the area in recent years that have brought some worrying signs despite their good intentions. Some examples of these public actions that have been caused some apprehension and concern include: the introduction of pedestrian areas and traffic restrictions without guaranteeing parking alternatives and full access for residents; the kind of (cultural) urban animation provided; the types of marketing campaigns conducted; the compulsory closing of some crucial agents (“nodes”) in the cultural life of the district; the impacts of public security policies on some sociability practices; or, notably, the kinds of urban renewal operations, with the development of certain real estate projects i.e. "private condominiums" thereby, increasing the danger of more serious gentrification processes.

Similarly, although the much more centralized public action in the Parque das Nações case is easier to understand and reproduce, it has its clear local specificities and cannot be uncritically transposed to any other cultural-led urban renewal experience. The public action, in the course of several varieties of policy-making, plays a fundamental role, but the everyday decisions (e.g. urban licensing, public spaces animation, etc.) must be specifically orientated to the particular circumstances of the local existing agents (the agents, their relations, their representations, their external networks), that are positively or negatively affected by these decisions at the time.

These outcomes enable us to question and assess the validity of our IM approach to this kind of study and the challenges it faces to explain this sort of situations. In other words, what conceptual advances could result from this application? As we have referred before (Costa, 2004, p.190), this application "raises the question of the sustainable management of the resource and the criteria that are (or must be) behind it. At least here, we consider that it clearly goes beyond strict economic and profitability rationality (even though embedded in cultural and historic specificities) [as traditionally recognized by IM approaches]. These criteria also have to be related to aesthetic affiliations, social distinction strategies or hedonistic behaviors, for instance, which have a profound effect on the actor's rationalities. In order to achieve sustainable development (and territorial competitiveness) in its various dimensions (economic efficiency, social equity, environmental quality, civic participation, cultural and identity expression), our innovative milieu management strategy must understand and promote this diversity of purposes and rationalities." And this is effectively a new challenge to the innovative milieu approach to territorial development.

DINÂMIA/CET - IUL, Centro de Estudos sobre a Mudança Socioeconómica e o Território 


\section{CONCLUDING NOTE: IMPLICATIONS FOR URBAN POLICIES}

Some implications for urban/metropolitan policies can be highlighted from our analysis of these two particular experiences in Lisbon together with the review of an extensive literature on creative cities and cultural-led territorial development strategies produced around the world in recent years.

Although it has not always been the dominant conviction, today there can be no question that cultural activities can and should be mobilized to promote regional/local development and competitiveness, and that these activities have particular potential to improve knowledge, innovation and creativity in contemporary economies (and to maintain the most creative classes and that add greatest economic value).

In terms of policy-action, therefore, the main idea to keep would be that urban development policies should consider the specific governance forms and the (self-)regulation mechanisms of each territorial system; then, each situation requires the design of a specific institutional solution, with or without public participation. This implies the development of specific political strategies, regarding concrete agents motivations and expectancies, and the planning of proper institutional solutions for each situation; and these should pay attention to the two main key-factors in the relation of these cultural systems with the city (capacity to generate creativity; capacity to develop governance mechanisms), in the framework of an effective densification of its cultural, artistic, economic and social fabric.

This leads us to some further considerations on urban/regional development and cultural policies. As we saw above, these policies cannot focus simply on organizing events, building facilities, improving infrastructure (or even on aiming to attract “creative classes”, a la Florida): They must also: (i) seize and take advantage of the spawned milieus, the ambiance, the networks, the institutions, the forms of regulation experimented; (ii) promote the accumulation of skills, know-how and the spread of innovation; (iii) create audiences and cultural routines, changing mentalities and encompassing multiculturalism and tolerance (iv) build consistent social representations together with collective image(s) and identity(ies).

That will be the way to promote, in a sustainable way, the densification and attraction of the creative classes and institutions; and it must be linked to the development of specific institutional models which adapt to the particular characteristics of that specific area of the city or to the individual stakeholders leading or personifying the cultural-led territorial dynamics.

In this context, some strategic guidelines for a territorialized cultural policy (that combines urban development and cultural policies) can be considered, in each particular situation. Amongst these guiding principles, we highlight the need to operate in conformity with the existing forms of regulation of the system (economic, social, creative-artistic, 
legitimization), in which these activities take place, whether they are the market, public intervention, or other governance forms (e.g. hierarchical relations of firms; personal networks; aesthetical affinities, etc.).

The multiple rationalities inherent to the action of all agents and the diversity of their motivations and expectations must not be forgotten. This involves economic motivations of course as well as others such as symbolic, aesthetic-creative, or social distinction motivations; these should all obviously be kept in mind by policy makers.

The focus must therefore be on a territorially-based action on the cultural production and consumption systems. Departing from the existing structures, agents or facilities, these specific competitive assets need to be explored in broader terms. As seen above, the need for a multidimensional intervention in this cluster must never be overlooked and transversal actuation (crossing, e.g., cultural, urban, training or transport authorities and policies) must be taken to face the same common problem, which requires good coordination.

Small practical changes must be made that are of incommensurable relevance to sustainability in the implementation of a creative city strategy or, in general, in the action towards a territorial-based cultural policy, at the different scales of intervention; for example, in the two case studies presented, we consider an explicit urban-level or metropolitan policy agenda is advisable. First, it must assume the importance and the strategic value of these activities in territorial development (and this also implies recognizing a broader concept of cultural activities, reaching their several diffuse margins), and to assume an effective urban cultural policy aiming to achieve the much debated "creative city". Secondly, the multiple dichotomies and dilemmas that usually affect public actuation in these field must be overcome and the dichotomist classical approaches in terms of cultural policies avoided (e.g., public/private, erudite/popular, permanent/ephemeral, local/central). Finally, a territoriallybased strategic articulation (and planning) must be promoted, involving the most relevant actors (the local ones and those with interest on the territory): among the several levels and institutions of public administration or between these and all the other agents in the cluster, in an effort to negotiate a common action strategy for the area. In a global world, this cannot rely only on endogenous factors; it must be done by improving the intervention in the several "intermediation zones" and regulation mechanisms that link the functioning of the cluster at the different scales. These "intermediation zones" define the specific conditions which allow the insertion of local agents in broader dynamics and establish the link between the local system and the "outer world" at the different scales and in several dimensions. And this is a crucial issue in symbolic-based activities and products such as cultural goods where aspects like the legitimization by the cultural gatekeepers or the embeddedness in own cultural identities are fundamentally determined by this local-global relation. 


\section{REFERENCES}

ASHEIM, B.; COENEN, L.; VANG-LAURIDSEN, J. (2007) Face-to-Face, Buzz and Knowledge Bases: Socio-Spatial Implications for Learning, Innovation and Innovation Policy, Forthcoming in Environment and Planning C.

BECKER, H. (1982) Art Worlds, Berkeley - Los Angeles - London: University of California Press.

BIANCHINI, F. (1999) Cultural planning for urban sustainability, in Nystrom, L. and C. Fudge (Ed.) (1999), City and Culture: Cultural processes and Urban Sustainability, Kalmar: The Swedish Urban Environment Council.

BIANCHINI, F. and M. PARKINSON (eds.) (1993), Cultural Policy and Urban Regeneration, Manchester: Manchester University Press, Manchester.

BIANCHINI, F., and C. LANDRY (1994), The Creative City. Working paper 3: Indicators of Creative City, A methodology for Assessing Urban Viability and Vitality. London: Comedia.

CAMAGNI, R., MAILLAT, D., MATTEACCIOLLI, A. (Eds.) (2004) Ressources naturelles et culturelles, milieux et développement local. Neuchâtel: EDES.

CAVES, R. (2002) Creative Industries: Contracts between Art and Commerce. Cambridge /London: Harvard University Press.

COSTA, P. (2003), As actividades culturais e a competitividade territorial: o caso da Área Metropolitana de Lisboa. Universidade Técnica de Lisboa. Dissertação de Doutoramento em Planeamento Regional e Urbano. Lisboa: ISEG/UTL.

COSTA, P. (2003a), Efeitos de meio e desenvolvimento sustentável num bairro cultural: a zona "Bairro Alto-Chiado - Relatório Final. Lisboa: CIRIUS/ISEG/UTL e CML.

COSTA, P. (2004), Milieu effects and sustainable development in a cultural quarter: the Bairro Alto - Chiado area in Lisbon, in: Camagni, R., D. Maillat, A. Matteaccioli (eds), Ressources naturelles et culturelles, milieux et développement local. Neuchâtel: EDES. pp. 157-193.

COSTA, P.; MAGALHÃES, M.; VASCONCELOS, B., SUGAHARA, G. (2006) On 'Creative Cities’ governance models: a comparative approach, Dinâmia Working Paper, nº2006/54, Lisboa: Dinâmia/ISCTE. 
COSTA, P. (2007) Creativity, innovation and territorial agglomeration in cultural activities: the roots of the creative city, forthcoming in Cooke, P. and L. Lazzeretti (Eds), Creative Cities, Cultural Clusters and Local Economic Development. Cheltenham: Edward Elgar.

CRANE, D. (1992) The Production of Culture: Media and the Urban Arts, Newbury Park: Sage.

CREVOISIER, O and R. CAMAGNI (Eds) (2000) Les milieux urbains: innovation, systèmes de production et ancrage. Neuchâtel: IRER.

DiMAGGIO, P. (1987) Classification in art, American Sociological Review, 1987, vol. 52, August, pp. 440-455.

EBERT, R.; GNAD, F.; KUNZMANN, K. (1994) The Creative City. Working Paper 2: Concepts and Preconditions of a Creative City, London: Comedia.

EC/KEA (2006) The Economy of Culture in Europe, Study prepared for the European Commission (Directorate-General for Education and Culture), October 2006, Brussels: EC.

ERICarts (2002) Creative Europe: On Governance and Management of Artistic Creativity in Europe. Bonn: European Research Institute for Comparative Cultural Policy and the Arts (ERICarts).

FLORIDA, R. (2002) The rise of the creative class, New York: Basic Books.

GREFFE, X. (2002) Art et artistes au miroir de l'économie, Paris: Editions UNESCO / Economica.

HALL, P. (2000) Creative Cities and Economic Development. Urban Studies, Vol. 37, No. 4, 639-649.

HANDKE, C. (2004) Defining creative industries by comparing the creation of novelty, RECIDA Working Paper No. 2. Rotterdam: Faculty of History and the Arts, Erasmus University Rotterdam.

HEALEY, P, (2004) Creativity and Urban Governance, Policy Studies, Vol. 25, No 2.

HOSPERS, G. (2003) Creative Cities: Breeding Places in the Knowledge Economy, Knowledge, Technology, \& Policy, Vol. 16, No. 3, 143-162. 
HUTTON, T. (2000) Reconstructed production landscapes in the post-modern city: applied design and creative services in the metropolitan core, Urban Geography, 2000, 21, 4, pp 285317.

LANDRY, C. (2000) The Creative City: a toolkit for urban innovators. London: Comedia / Earthscan.

LAVANGA, M. (2003) Creativity, Cultural Quarters and Urban Development', in Proceedings of the conference Workshop on Aesthetics, Art and Management: Towards new Fields of Flow (EIAMS), Gattières, France.

LAZZERETTI, L. (Ed.) (2004), Art Cities, Cultural Districts and Museums, Firenze: Firenze University Press.

MAILLAT, D. (1998) Interactions between urban systems and localized productive systems: an approach to endogenous regional development in terms of innovative milieu, European Planning Studies, Vol. 6, No. 2, pp. 117-129.

MARKUSEN, A. (2006) Urban development and the Politics of a Creative Class: Evidence from the Study of Artists, Environment and Planning A, Vol. 38, No. 10:1921-1940.

MARKUSEN, A. (2006a) Cultural Planning and the Creative City" 2006. Working Paper \#271, Project on Regional and Industrial Economics, Humphrey Institute of Public Affairs, University of Minnesota (Presented at the annual meetings of American Collegiate Schools of Planning, Ft. Worth, Texas, November 12, 2006).

MARKUSEN, A. and G. SCHROCK (2006) The Artistic Dividend: Urban Artistic Specialization and Economic Development Implications, Urban Studies, Volume 43, N. 10: 1661 - 1686.

NESTA (2006) Creating Growth - How the UK can develop world class creative business, London: NESTA Research Report.

O'CONNOR, J. and D. WYNNE (ed.) (1996) From the Margins to the Centre: Cultural production and consumption in the post-industrial city, Aldershot: Arena.

OECD (2005) Culture and Local Development, Paris: OECD.

\footnotetext{
DINÂMIA/CET - IUL, Centro de Estudos sobre a Mudança Socioeconómica e o Território ISCTE-IUL - Av. das Forças Armadas, 1649-026 Lisboa, PORTUGAL Tel. 217938638 Fax. 217940042 E-mail: dinamia@iscte.pt www.dinamiacet.iscte.pt
} 
PRATT, A. (2004) Mapping the Cultural Industries: Regionalisation; The Example of South East England, in Scott, A. J. and D. Power, The Cultural Industries and the Production of Culture, London: Routledge.

SANTAGATA, W. (2002) Cultural Districts, Property Rights and Sustainable Economic Growth, International Journal of Urban and Regional Research, Volume 26.1, March 2002, pp.9-23.

SCOTT, A. J. (2000) The Cultural Economy of Cities, New Delhi, London- Thousand Oaks: Sage.

SCOTT, A. J. (2006) Creative Cities: Conceptual issues and Policy Questions, Journal of Urban Affairs, Volume 28, Number 1, pp. 1-17.

SHAPIRO, D.; ABERCROMBIE, N.; LASH, S.; LURY, C. (1992) Flexible specialization in the culture industries, in Ernste, H. and V. Meier (Eds.), Regional development and contemporary industrial response: extending flexible specialization, London / New York: Belhaven, pp. 179-194.

STORPER, M. and S. CHRISTOPHERSON (1987) Flexible Specialization and Regional Industrial Agglomerations: The Case of US Motion Picture Industry, Annals of the Association of American Geographers, 77 (1), pp. 104-117.

THROSBY, D. (2001) Economics and Culture. Cambridge: Cambridge University Press.

TOWSE, R. (Ed.) (2003) A handbook of cultural economics. Northampton: Edward Elgar.

TOWSE, R. (2004) “Towards an economics of creativity”. RECIDA Working Paper No. 1. Rotterdam: Faculty of History and the Arts, Erasmus University Rotterdam.

ZUKIN, S. (1995), The Cultures of Cities, Cambridge / Oxford: Blackwell. 